IRA-International Journal of Technology \& Engineering

ISSN 2455-4480; Vol.03, Issue 03 (2016)

Institute of Research Advances

http://research-advances.org/index.php/IRAJTE

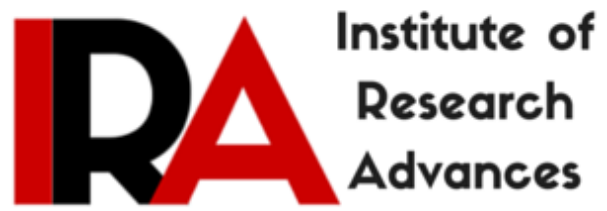

\title{
Effect of substrate geometry on oil sorption capacity of raw and chemically modified jute fibre
}

\author{
Mangesh D. Teli \& Sanket P. Valia \\ Department of Fibres and Textile Processing Technology, \\ Institute of Chemical Technology \\ Matunga (E), Mumbai-400019, India .
}

DOI: http://dx.doi.org/10.21013/jte.v3.n3.p4

How to cite this paper:

Teli, M., \& Valia, S. (2016). Effect of substrate geometry on oil sorption capacity of raw and chemically modified jute fibre. IRA-International Journal of Technology \& Engineering (ISSN 2455-4480), 3(3). doi:http://dx.doi.org/10.21013/jte.v3.n3.p4

(C) Institute of Research Advances

\section{(cc) EY-NC}

This works is licensed under a Creative Commons Attribution-Non Commercial 4.0 International License subject to proper citation to the publication source of the work.

Disclaimer: The scholarly papers as reviewed and published by the Institute of Research Advances (IRA) are the views and opinions of their respective authors and are not the views or opinions of the IRA. The IRA disclaims of any harm or loss caused due to the published content to any party. 


\begin{abstract}
In this paper jute fibre was modified with three different chemical modification techniques namely acetylation using acetic anhydride, grafting using butyl acrylate monomer and fatty acid modification using oleic acid to increase the oil sorption capacity of the fibre. All the above modifications were carried out in fibrous as well as nonwoven form to study the effect of substrate geometry on oil sorption capacity. It was found that oil sorption capacity of the chemically modified jute fibres was higher than that of the raw fibres and in case of the chemically modified nonwoven it was much higher than the raw as well as modified loose fibres. Reusability of the modified substrates was also tested and it was found that all the substrates could be squeezed to recover oil and reused at least three times. Nonwoven fabric's substrate geometry permits easy rolling-in and rolling-out of the fabric for the recovery of the oil from the surface of the water. Also these oil sorption-active materials being biodegradable can be used to substitute non-biodegradable synthetic materials in oil spill cleanup.
\end{abstract}

Keywords: Jute fibre, nonwoven, acetylation, grafting, oil sorption

\title{
1. Introduction
}

Oil based products, derived from crude oil have become inevitable for mankind and their dependency on such products is increasing day by day. These products are used to fuel automobiles, heat homes, produce energy and are used for machinery in various industries. Some of the products that come from petroleum are gasoline, diesel, motor oil, kerosene, jet oil, heating oil, asphalt, and plastics. Transportation by sea route is the most economical and accounts for large volumes of oil through ships from different oil extracting countries to heavily populated countries where such demand is very high throughout the year. However, sometimes oil gets spilled into water during loading, transportation and unloading. Hence oil spills are continuing problems throughout the world [1].

Thus, various processes have been developed to remove oil from contaminated areas by use of booms, dispersants and skimmers, oil water separator or by use of different kinds of sorbent material [2]. The main limitations of some of these techniques are their high cost and recovery of oil [3]. Most commonly used commercial sorbents are synthetic sorbents made of polypropylene or polyurethane [4]. They have good hydrophobic and oleophilic properties, they have high oil sorption capacity and low water uptake and thus, they are ideal materials for oil recovery from the water surface but their non biodegradability is a major limitation $[5,6]$. A biodegradable material with excellent absorption properties would be advantageous in this respect. A number of natural sorbents have been studied for use in oil-spill cleanup, e.g. cotton [7], wool [8] and bark [9] which can be excellent oil sorbent because of its hydrophobic and oleophilic character. As cotton is primarily used for apparels and is quite expensive, alternative lignocellulosic fibres must be explored which can be used for cleaning up the oil spills. One such natural, abundantly available, economical lignocellulosic fibre is jute.

Jute is a bast fibre composed of cellulose and lignin, hence it is considered to be lignocellulosic fibre. Jute has unique physical characteristics like high tenacity, bulkiness, acoustic insulation, low thermal conductivity and antistatic properties. Jute shows a high moisture regain of about $12-13 \%$ under standard conditions of temperature and humidity. 
On absorption of moisture, these fibres swell, ultimately increasing the thickness of the fibre [10]. Like other natural fibres, jute fibres degrade in moist conditions and thus can be used in geo-textile applications by providing reinforcement for a limited period of time.

Although the majority of nonwoven materials are produced from man-made fibres, the trend towards more environment-friendly products incorporating recyclability and biodegradability means that jute and other plant fibres can be more widely used. Jute is the second most important natural fibre consumed globally [11]. Jute nonwovens offer good sound absorption (Thilagavathi et al., 2010) [12]. Generally, the webs of jute fibres are manufactured by using carding technology. The nonwovens prepared from jute fibres are generally bonded by using needle-punching technology, thermal-bonding with the help of binder fibres and chemical-bonding are also employed (Debnath et al., 2011) [13]. Key characteristics include silky lustre, low extensibility, high friction, easy biodegradability and environment friendliness, high moisture absorption and thermal and electrical insulation.

The hydrophilic property of jute fibre which is a barrier for oil sorption can be reduced significantly by chemical modification of its constituents. Some of the methods used for making the fibre hydrophobic and oleophilic are acetylation, grafting and fatty acid modification, particularly for the production of novel materials which can be utilized for oil sorption. The objective of this research was to modify the jute substrate in fibrous and nonwoven form with different techniques of chemical modification and study their effect on oil sorption capacity.

\section{Materials and Methods}

\subsection{Materials}

Jute fibre was obtained from CIRCOT (Mumbai, India) and the jute nonwoven was obtained from BTRA (Mumbai, India). The fibre was cleaned manually washed with distilled water to remove dirt, mud and other water soluble impurities. These fibres were dried in hot air oven at $60^{\circ} \mathrm{C}$ for $24 \mathrm{hr}$. Acetic anhydride was purchased from Thomas Baker and N-Bromosuccinimide (NBS), Oleic acid, butyl acrylate monomer, potassium persulphate (KPS), N, N-methylene-bis-acrylamide and all other chemicals were purchased from S.D Fine Chemicals Mumbai India. High density oil used for the testing purpose was supplied by HPCL, Mumbai, India.

\subsection{Methods}

\subsubsection{Acetylation in a Solvent Free System}

Jute in fibrous form and nonwoven form was modified by acetylation, using all the optimized conditions reported in our earlier work [13].

A fixed quantity of jute fibre $(10 \mathrm{~g})$ was placed in a $500 \mathrm{ml}$ round bottom flask containing required $\mathrm{ml}$ of acetic anhydride (1:20) and NBS (2\%) as a catalyst. The flask was then placed in an oil bath set at $120^{\circ} \mathrm{C}$ temperature using atmospheric pressure with a reflux condenser fitted. The reaction was continued for $1 \mathrm{hr}$ at the $120^{\circ} \mathrm{C}$ and than the flask was removed from the oil bath and the hot reagent was decanted-off. The jute fibre was then thoroughly washed with ethanol and acetone to remove the un-reacted acetic anhydride and acetic acid by-products. The modified fibres were then dried in an oven at $60^{\circ} \mathrm{C}$ to constant weight. The oven-dry fibre samples were weighed to determine the weight gains on the basis of initial oven-dry weight. Weight percent gain of the jute fibre due to acetylation was calculated using the formula:

$$
W P G=\frac{W_{2}-W_{1}}{W_{1}} \times 100
$$


Wherein, $\mathrm{W}_{1}$ and $\mathrm{W}_{2}$ are the weights of jute fibre and acetylated jute fibre, respectively. 2.2.2. Graft copolymerization of butyl acrylate on to jute fibre and nonwoven Jute in fibrous form and nonwoven form was modified by graft copolymerization technique using all the optimized conditions reported by Teli et al. 2016 [15].

The grafting reaction was carried out in a three neck round bottom flask. To control the reaction temperature, the flask was placed in a thermo stated heating mantle. The required weight $(10 \mathrm{gm})$ of jute substrates and butyl acrylate monomer $(150 \%)$ were taken in the flask and agitated for $10 \mathrm{~min}$. The cross linking agent $\mathrm{N}, \mathrm{N}$-methylene-bisacrylamide $(0.05 \%)$ and initiator potassium per sulphate $(0.1 \%)$ were then added to the flask. The reaction was carried out under nitrogen atmosphere and the mixture was stirred continuously for $3 \mathrm{~h}$. The homopolymer formed during the graft copolymerization reaction, was separated from the grafted copolymer by stirring for $12 \mathrm{~h}$ in ethyl alcohol for complete removal of homopolymer. The samples were dried in oven at $50^{\circ} \mathrm{C}$, and weighed.

Graft add - on $(\%)=\frac{\mathrm{W}_{2}-\mathrm{W}_{1}}{\mathrm{~W}_{1}} \times 100$

\subsubsection{Preparation of fatty acid-modified jute fibre and nonwoven}

Jute in fibrous form and nonwoven form was modified using fatty acid using all the optimized conditions reported in our earlier work [16].

One gram of jute substrate was treated with the required amount of fatty acid in the presence of 1-3 drops of concentrated sulfuric acid as catalyst. The mixture was refluxed in a Dean-Stark apparatus at the required temperature for an optimized period of time. The treated material was washed with n-hexane, followed by drying in an oven at $70^{\circ} \mathrm{C}$ till constant weight, and then was stored in an air tight container until further use. The amount of reacted fatty acid was estimated by weight percent gain (WPG), using the following equation:

$W P G=\frac{W_{2}-W_{1}}{W_{1}} \times 100$

where $\mathrm{W} 2$ andW1 are the weights of fibre after and before reaction, respectively.

\subsubsection{Oil sorption capacity}

Oil absorption was determined by using method reported in literature [17]. A fixed quantity of crude oil $(50 \mathrm{~g})$ was suspended in water in a beaker. The modified jute substrate $(1 \mathrm{~g})$ was added at room temperature and allowed to absorb oil for $1 \mathrm{hr}$. The substrate was then removed and held to drain off the excess amount of oil. The material was then reweighed to determine the oil absorption.

\subsubsection{Recovery of sorbed oil and reusability of sorbents}

In order to examine the reusability of these sorbents, method described by [18] was followed which has limitation that gives only an approximate value of oil sorption. In this method machine oil $(50 \mathrm{~g})$ was suspended in water in a beaker. The modified jute substrate $(1 \mathrm{~g})$ was added and mixed for $1 \mathrm{~min}$ at room temperature and allowed to absorb oil for $1 \mathrm{hr}$. The sorbent with oil was weighed and then squeezed between two rollers at a pressure of $10 \mathrm{kgf} / \mathrm{cm}^{2}$ before it was reweighed to determine the amount of oil recovered. The squeezed sorbent was again used in the sorption process as before. The efficiency of 
sorbent reusability was determined by oil sorption capacity of each sorbent after repeated sorption and mechanical desorption cycles [19].

\section{Results and Discussion}

Results in Table 1 indicate that on acetylation, jute fibres showed oil absorption capacity of $21.08 \mathrm{~g} / \mathrm{g}$ which is far higher than that of the unmodified jute fibre $(2.58 \mathrm{~g} / \mathrm{g})$. In other words oil absorption capacity of jute fibres increased by $717 \%$ on acetylation. Such enhanced oil absorbency is attributed to acetylation which increases the oleophilicity of hygroscopic material. The hydroxyl groups of the lingo-cellulosic material react with acetic anhydride and form esters of lignin, cellulose and hemicellulose which in turn impart hydrophobicity as well as oleophilicity [20].

It is reported from our laboratory that raw jute nonwoven material absorbed $8.63 \mathrm{~g} / \mathrm{g}$ [14] of oil which is $296 \%$ higher than that when it is used in loose fibrous form. The plausible reason for such high increase in oil sorption capacity of the nonwoven is due to its geometry. Nonwoven materials are structures made from fibrous webs, which contain small pores and thus facilitate the transport of liquids into the sorbents and retain the liquids after sorption [21].

When this nonwoven material is acetylated using the optimized conditions mentioned below in Table 1, it shows oil sorption capacity of $24.56 \mathrm{~g} / \mathrm{g}$ which is higher than that of unmodified nonwoven material $(8.63 \mathrm{~g} / \mathrm{g})$ as well as the modified material in fibrous form $(21.08 \mathrm{~g} / \mathrm{g})$. Hence, the oil sorption capacity of acetylated nonwoven increased by $140.31 \%$ on acetylation. In other words acetylated jute nonwoven showed maximum oil sorption capacity and this is due to acetylation of jute fibres which increased the oleophilicity of these fibres and secondly is due to the change in structural geometry of the substrate.

The reusability of the acetylated jute fibre and nonwoven was examined by simple squeezing method. This method is a common, practical, and economical method of recovering the oil. The results in Table 1 indicate that even after using the sorbents for three cycles the acetylated jute fibre and nonwoven could absorb $42.74 \%$ and $62.45 \%$ of oil, respectively as compared to their oil absorption values when fresh samples were used. The sorbents could be reused for at least three cycles. The results, however, showed that the oil sorption in the first cycle was higher and in the subsequent cycles it is reduced gradually because of the the disruption and collapsing of tubular and porous structure of interior fibre during the mechanical squeezing. However, acetylated nonwoven material showed better oil sorption and recovery at the end of third cycle because the holding capacity of the nonwoven substrate is better than fibres in loose form.

\section{Table 1 Oil sorption capacity and reusability of acetylated jute fibre and jute nonwoven (See Tables \& Figures section)}

Similarly jute fibre and jute nonwoven were grafted using butyl acrylate as monomer using the conditions optimized and reported by Teli et al. [15]. It was found that on grafting of jute fibres the oil sorption capacity of jute fibres increased to $14.16 \mathrm{~g} / \mathrm{g}$ which is $448.3 \%$ more than unmodified jute fibre, while in case of grafted jute nonwoven the oil sorption capacity was $19.20 \mathrm{~g} / \mathrm{g}$ which is $122.47 \%$ more than unmodified jute nonwoven (Refer Table 2). The feasible reason could be the hydrophobicity imparted as a result of modification with butyl acrylate monomer; also the cross linker used in the reaction helps in forming the interpenetrating network which helps in holding the oil sorbed. Results from Table 2 also indicate that the grafted fibres and grafted jute nonwoven can be reused for at least 3 times before disposing them. 
Table 2 Oil sorption capacity and reusability of butyl acrylate grafted jute fibre and nonwoven (See Tables \& Figures section)

Results from Table 3, indicate that jute in fibrous form and nonwoven were modified using oleic acid using the optimized conditions as reported by Teli et al. [16]. It was found that oil sorption capacity of modified fibre was $14.78 \mathrm{~g} / \mathrm{g}$ while in case of modified nonwoven was $18.33 \mathrm{~g} / \mathrm{g}$ which is far more than that of the unmodified fibre and nonwoven respectively. The justification behind such high increase in oil sorption capacity is that, it occurs due to the replacement of hydroxyl groups in the cell wall of the jute fibres, by heavier, more hydrophobic acetyl groups. Thus, modification of the jute substrates with oleic acid imparts oleophilic properties to the fibre. This modified material had very little affinity for water and strong affinity for oil.

Reusability of the substrate is also reported in Table 3 and it is found that the fatty acid modified jute substrates show higher oil uptake in the first cycle and then its sorption capacity decreased significantly in the subsequent cycles. This may be due the collapsing of lumen during the mechanical squeezing [22] and masking of acetyl groups in modified materials. Thus the capacity of oil sorption decreased from $14.78 \mathrm{~g} / \mathrm{g}$ to $8.02 \mathrm{~g} / \mathrm{g}$ for jute fibres and $18.33 \mathrm{~g} / \mathrm{g}$ to $12.95 \mathrm{~g} / \mathrm{g}$ for modified jute nonwoven in the third cycle as show in Table 3. However, even after 3 cycles of the use, modified jute material whether in fibre or nonwoven form is much more oil sorbent than their unmodified counterpart.

\section{Table 3 Oil sorption capacity and reusability of oleic acid modified jute fibre and nonwoven (See Tables \& Figures section)}

\section{Conclusion}

It can be concluded, that the jute nonwoven fabric modified with various methods showed higher oil sorption capacity as compared to the jute fibres. These nonwoven materials enable efficient, effective and economic oil containment and recovery of the oil from the spilled area. It can be also concluded that chemical modification i.e. acetylation has greater impact on oil sorption capacity than the other two methods. Nonwovens can be effectively used as oil sorbent for it can give twofold advantage of being highly absorbent, biodegradable and also recovery of oil becomes easier. Nonwovens prepared from such materials can be used as pads, rolls which can be spread over the spilled surfaces and can be collected easily and reused for oil sorption. The cost of such products would be also quite low since, the low cost natural fibre jute is used which is also abundantly available.

\section{Acknowledgment}

I would like to thank University Grant Commission Special Assistance programme (UGC-SAP) for providing funds for carrying out this research.

\section{References}

1. Boufadel, M. C., Bobo, A. M., \& Xia, Y. (2011). Feasibility of deep nutrients delivery into a Prince William Sound beach for the bioremediation of the Exxon Valdez oil spill. Groundwater Monitoring \& Remediation, 31(2), 80-91.

2. Nahla A. T., (2008). Study on the use of barley straw for oil spill cleanup, A thesis presented to graduate school, Faculty of Engineering, Alexandria University. 
3. Wei, Q. F.; Mather, R. R; Fotheringham, A. F., (2005). Oil removal from used sorbents using a biosurfactant, Bioresource Tech., 96 (3), 331-334.

4. Teas, C.; Kalligeros, S.; Zanikos, F.; Stournas, S.; Lois, E.; Anastopoulos, G., (2001). Investigation of the effectiveness of absorbent materials in oil spills clean up., Desalination, 140 (3), 259-264.

5. Choi, H.; Cloud, R. M., (1992). Natural sorbents in oil spill cleanup., Environ. Sci. Tech., 26 (4), 772-776.

6. Deschamps, G.; Caruel, H.; Borredon, M. E.; Bonnin, C.; Vignoles, C., (2003). Oil removal from water by selective sorption on hydrophobic cotton fibres. 1 . Study of sorption properties and comparison with other cotton fibre-based sorbents, Environ. Sci. Tech., 37 (5), 1013-1015.

7. Johnson, R.; Manjrekar, T.; Halligan, J., (1973). Removal of oil from water surfaces by sorption on unstructured fibres., Environ. Sci. Tech., 7 (5), 439- 443.

8. Radetic, M.; Jocic, D.; Jovancic, P.; Petrovic, Z.; Thomas, H., (2003). Recycled wool-based nonwoven material as an oil sorbent., Environ. Sci. Tech. 37 (5), 1008-1012.

9. Haussard, M.; Gaballah, I.; Kanari, N.; de Donato, P.; Barre's, O.; Villieras, F., (2003). Separation of hydrocarbons and lipid from water using treated bark., Water Res., 37 (2), 362-374.

10. Debnath, S., \& Madhusoothanan, M. (2011). Thermal resistance and air permeability of jute-polypropylene blended needle-punched nonwoven. Indian Journal of Fibre and Textile Research, 36(2), 122.

11. Basu, G., \& Roy, A. N. (2008). Blending of jute with different natural fibres. Journal of Natural Fibres, 4(4), 13-29.

12. Thilagavathi, G., Pradeep, E., Kannaian, T., \& Sasikala, L. (2010). Development of natural fibre nonwovens for application as car interiors for noise control. Journal of Industrial Textiles, 39(3), 267-278.

13. Teli, M. D., \& Valia, S. P. (2013). Acetylation of Jute fibre to improve oil absorbency. Fibres and Polymers, 14(6), 915-919.

14. Teli, M.D. \& Valia S. P. (2013). Modification of Lignocellulosic Fibre for Enhanced Oleophilicity: International Journal of Advanced Engineering Applications, 2 (2), 65-71.

15. Teli, M.D. \& Valia S. P. (2016). Grafting of butyl acrylate on to banana fibres for improved oil absorption, Journal of Natural Fibres.

16. Teli, M. D., \& Valia, S. P. (2015). Modification of bio-materials for functional application. Scanning electron microscopy (SEM), 900, 1.

17. Sun XF, Sun RC, and Sun JX (2004). Acetylation of sugarcane bagasse using NBS as a catalyst under mild reaction conditions for the production of oil sorption-active materials. Bioresource

Technology, 95, 343-350.

18. Choi HM, and Moreau JP (1993). Oil sorption behaviour of various sorbents studied by sorption capacity measurement and environmental scanning electron microscopy. Microscopy Research and Technique, 25, 447-455.

19. Ansari IA, East GC, Johnson DJ (2003) Structure-Property Relationships in Natural Cellulosic Fibres: Part III: Flax-an Oil Sorbent. Journal of the Textile Institute, 94: 1-15.

20. Nwankwere, E. T., Omolaoye, J. A., Nwadiogbu, J. O., \& Nale, B. Y. (2011). Thermal and dimensional stability of NBS-catalyzed acetylated rice husks. Der Chemica Sinica, (2), 1. 
21. Karan, C. P., Rengasamy, R. S., \& Das, D. (2011). Oil spill cleanup by structured fibre assembly. Indian Journal of Fibre \& Textile Research, 36(2), 190-200.

22. Hill, CAS., Jones, D., Strickland, G., \& Cetin, N. S. (1998). Kinetic and mechanistic aspects of the acetylation of wood with acetic anhydride. Holzforschung, 52, 623-629. 


\section{Tables \& Figures}

Table 1 Oil sorption capacity and reusability of acetylated jute fibre and jute nonwoven

\begin{tabular}{|c|c|c|c|c|}
\hline \multirow{2}{*}{ Substrate } & \multirow{2}{*}{$\begin{array}{c}\text { Oil } \\
\text { sorption } \\
\text { raw fibre } \\
\text { (g of oil/g } \\
\text { of } \\
\text { substrate) } \\
\end{array}$} & \multicolumn{3}{|c|}{$\begin{array}{l}\text { Oil sorption of modified substrate } \\
\text { (g of oil/g of substrate) }\end{array}$} \\
\hline & & $1^{\text {st }}$ Cycle & $2^{\text {nd }}$ Cycle & $3^{\text {rd }}$ Cycle \\
\hline Jute fibre & 2.58 & $\begin{array}{c}21.08 \\
(717 \%) \\
\end{array}$ & $\begin{array}{c}13.68 \\
(430.23 \%) \\
\end{array}$ & $\begin{array}{c}9.01 \\
(250.77 \%) \\
\end{array}$ \\
\hline Jute Nonwoven & 8.63 & $\begin{array}{c}24.56 \\
(184.58 \%) \\
\end{array}$ & $\begin{array}{c}20.72 \\
(140.09 \%) \\
\end{array}$ & $\begin{array}{c}15.34 \\
(77.75 \%) \\
\end{array}$ \\
\hline $\begin{array}{l}\text { Increase in oil } \\
\text { sorption } \\
\text { because of } \\
\text { change in } \\
\text { geometry }(\%)\end{array}$ & 222.86 & 16.50 & 33.97 & 41.26 \\
\hline
\end{tabular}

Table 2 Oil sorption capacity and reusability of butyl acrylate grafted jute fibre and nonwoven

\begin{tabular}{|c|c|c|c|c|}
\hline \multirow{2}{*}{ Substrate } & $\begin{array}{c}\text { Oil sorption raw } \\
\text { fibre } \\
\text { (g of oil/g of } \\
\text { substrate) }\end{array}$ & \multicolumn{3}{|c|}{$\begin{array}{c}\text { Oil sorption } \\
\text { (g of oil/g of substrate) }\end{array}$} \\
\cline { 3 - 5 } Jute fibre & 2.58 & $\mathbf{1}^{\text {st }}$ cycle & $\mathbf{2}^{\text {nd }}$ cycle & $\mathbf{3}^{\text {rd }}$ cycle \\
\hline Jute Nonwoven & 8.63 & 14.16 & 10.12 & 8.27 \\
$(448.83 \%)$ & $(292.24 \%)$ & $(220.54 \%)$ \\
\hline $\begin{array}{c}\text { Increase in oil } \\
\text { sorption because } \\
\text { of change in } \\
\text { geometry (\%) }\end{array}$ & 222.86 & 35.59 & 15.45 & $\begin{array}{c}12.67 \\
(122.47 \%)\end{array}$ \\
\hline
\end{tabular}


Table 3 Oil sorption capacity and reusability of oleic acid modified jute fibre and nonwoven

\begin{tabular}{|c|c|c|c|c|}
\hline \multirow{2}{*}{ Substrate } & $\begin{array}{c}\text { Oil sorption raw } \\
\text { fibre } \\
\text { (g of oil/g of } \\
\text { substrate) }\end{array}$ & \multicolumn{3}{|c|}{$\begin{array}{c}\text { Oil sorption } \\
\text { (g of oil/g of substrate) }\end{array}$} \\
\cline { 3 - 5 } Jute fibre & 2.58 & $\mathbf{1}^{\text {st }}$ cycle & $\mathbf{2}^{\text {nd }}$ cycle & $\mathbf{3}^{\text {rd }}$ cycle \\
\hline Jute Nonwoven & 8.63 & $\begin{array}{c}14.78 \\
(472.86 \%)\end{array}$ & $\begin{array}{c}11.12 \\
(331 \%)\end{array}$ & $\begin{array}{c}8.02 \\
(210.85 \%)\end{array}$ \\
\hline $\begin{array}{c}\text { Increase in oil } \\
\text { sorption because } \\
\text { of change in } \\
\text { geometry (\%) }\end{array}$ & 222.86 & 24 & 15.27 & 12.95 \\
\hline & & $(112.39 \%)$ & $(76.94 \%)$ & $(50.05 \%)$ \\
\hline
\end{tabular}

